\title{
Knowledge of complementary feed and its effect on the child nutrition
}

\author{
Venugopal. S ${ }^{1}$, Chandrashekar ${ }^{2}$ \\ ${ }^{1}$ Dr Venugopal.S , Assistant professor Department of Pediatrics, ${ }^{2}$ Dr Chandrashekar, Associate professor, Department of \\ pediatrics, Shivamogga Institute of Medical Sciences, Shivamogga, Karnataka, India.
}

Address for correspondence: Dr Venugopal.S Email; drvenugopalped@gmail.com \#204 Mac Gann hospital staff quarters , Shivamogga Institute of Medical Sciences, Shivamogga, Karnataka

\begin{abstract}
Introduction: Introduction of semisolid food in an infant who is on liquid diet is known as complementary feeding. When breast milk is no longer enough to meet the nutritional needs of the infant, complementary feeding should be started. Methods: 500 mothers with children 6-24 months of age attending OPD in Mc Gann were interviewed. Data was collected using a self-administered, semi-structured questionnaire with the mothers regarding knowledge, attitude, and practices of complementary feeding Results: Knowledge, attitude and practices were assessed in 500 mothers. The mean age of complementary feeding was $8.24 \pm 2.79$ months. Only few had correct information from health personnel. $23 \%$ of mothers started complementary feeding at 6 months of age. $21.6 \%$ of mothers used commercial foods. Male child, illiterate mothers, low socio-economic group and rural mothers tend to wean late $(\mathrm{p}<0.001)$. Parity, had no influence on complementary feeding age $(\mathrm{p}>0.05) .34 .1 \%, 34.5 \%$ and $23.8 \%$ of children were under weight, stunted and wasted respectively. There was significant association between delayed complementary feeding and malnutrition of the child. Conclusion: There is lack of knowledge in mothers regarding complementary feeding, there has to be proper recommendation about timing of complementary feeding. Mean age of complementary feeding was delayed due to improper information, false beliefs and attitudes, illiteracy, low socio-economic status and rural mothers, thus leading to malnutrition of the child. Hence, mothers should be educated properly regarding complementary feeding, foods, preparation and practice to prevent malnutrition and improve the health status of the children.
\end{abstract}

Key words: Complementary feeding, Attitude, stunted, wasted, Malnutrition.

\section{Introduction}

Introduction of semisolid food in an infant who is on liquid diet is known as complementary feeding. When breast milk is no longer enough to meet the nutritional needs of the infant, complementary feeding should be started. When breast milk is no longer enough to meet the nutritional needs of the infant, complementary feeding or complementary feeding should be started [1]. The transition from exclusive breast feeding to semisolid foods is a very vulnerable period because it is the time when malnutrition starts in many infants, contributing significantly to the high prevalence of malnutrition and infection in children under five years of age worldwide [2].

Manuscript received: $19^{\mathrm{TH}}$ Dec 2015

Reviewed: $30^{\text {th }}$ Dec 2015

Author Corrected; $09^{\text {th }}$ Jan 2016

Accepted for Publication: $17^{\text {th }}$ Jan 2016
Timely complementary feeding is an important process in every child which has an impact on future health, growth and development of the child.Complementary feeding also marks the beginning of the child developing some degree of independence. Complementary feeding foods should be adequate in nutrition, appropriate in consistency, given in sufficient quantity and hygienic. According to the WHO guidelines complementary feeding should be started at 6 months of age along with breast feeding up to 2 years or more [3].

Tough job among mothers for the mother is complementary feeding. Understanding the decision making process, beliefs, knowledge, attitude and practices of complementary feeding and factors influencing complementary feeding is an important step 
prior to designing an intervention strategy to affect change in behavior.

Improper complementary feeding or complementary feeding practices, coupled with high rates of infectious diseases, are the principal proximate causes of malnutrition during the first two years of life [4].

For this reason, it is essential to ensure that mothers and caregivers are provided with appropriate guidance regarding optimal feeding of infants and young children.

\section{Aims and Objectives}

1. To know the mean age of complementary feeding

2. To know various factors influencing age of complementary feeding like parity, education, occupation, socioeconomic status, sex of the child.

3. Age of complementary feeding started and its effect on growth of the child.

\section{Methodology}

Source of data: Mothers with children aged 6 to 24 months were included in this study based on convenience who was attending for immunization in Mc Gann government hospital. Mothers of selected children who were willing to participate in the study were interviewed for collecting data after informed consent.

Sample size: 500 mothers, with children aged 6 to 24 months.

Study design: Prospective study.

Method of collection of data:Data was collected from the mothers using a self administered, predesigned semi-structured questionnaire with the mothers regarding demographic profile, knowledge, attitude and practices of complementary feeding, source of information and factors influencing age of complementary feeding like parity (primi or multigravida), education (literate or illiterate), occupation (working or house wife), socio-economic status, sex of the child, religion and residence (urban or rural). Mothers who were able to read or write with understanding in any one language were considered literate. Socio-economic status and was classified into five classes using modified Kuppuswamy classification.

Anthropometric parameters (weight and length) were recorded. Weight was measured with minimal clothing and length was measured in recumbent position. The weight and length measurements were converted into three summary indices of nutritional status: weight-forage, length-for-age and weight-for-length.

According to WHO, (children who were more than two standard deviations below the reference median on the basis of weight-for-age, length-for-age and weight-forlength indices were considered respectively to be underweight, stunted and wasted) [5]. Based on standard deviation (SD) units (termed as Z-scores),

\section{Inclusion criteria:}

- Mothers having children of age between 6 to 24 months.

\section{Exclusion criteria:}

- Mothers with children of aged less than 6 months and more than 24 months.

- Top fed babies since birth due to various reasons.

Statistical analysis: The information was collected and analyzed through SPSS statistical software version11.5. Mean, range, standard deviation, frequency and percentages were calculated. Z-test was used for testing the association between mean age of complementary feeding with different attributes and $\mathrm{p}$ value calculated.

The $\mathrm{p}$ value $<0.05$ was considered significant and $\mathrm{p}<$ 0.001 was considered highly significant. Unpaired t-test was used to find association between mean age of complementary feeding and various classes of socioeconomic status groups. The $\mathrm{Z}$ scores for anthropometry were derived using the WHO Anthro software, which is based on the NCHS/WHO international growth curves[5].

\section{Results}

500 mothers having children between 6 to 24 months of age were interviewed. Table below shows the sociodemographic profile of this study population. 
Table -1: Socio Demographic Characteristics

\begin{tabular}{|c|c|c|c|}
\hline Variable $(n=500)$ & Frequency \% & Variable $(n=500)$ & Frequency \% \\
\hline \multicolumn{2}{|l|}{ Age of child } & \multicolumn{2}{|l|}{ Socio economic status } \\
\hline $6-12$ months & $182(36.4)$ & & \\
\hline $13-18$ months & $131(26.2)$ & Class I & $8(1.6)$ \\
\hline $19-24$ months & $187(37.4)$ & Class II & $53(10.6)$ \\
\hline Sex & & Class III & $163(32.6)$ \\
\hline Male & $269(53.8)$ & Class IV & $221(44.2)$ \\
\hline Female & $231(46.2)$ & Class V & $55(11.0)$ \\
\hline \multicolumn{4}{|l|}{ Mothers education } \\
\hline Literate & $276(55.2)$ & Malnutrition & \\
\hline Illiterate & $224(44.8)$ & & \\
\hline Mothers occupation & & Under weight & 34.1 \\
\hline Working & $102(20.4)$ & Stunted & 34.5 \\
\hline House wife & $398(79.6)$ & Wasted & 23.8 \\
\hline \multicolumn{4}{|l|}{ Residence } \\
\hline Urban & $228(45.6)$ & & \\
\hline Rural & $272(54.4)$ & & \\
\hline
\end{tabular}

Mean age of knowledge regarding complementary feeding was $7.99 \pm 2.48$ months and range $4-20$ months. $44.6 \%$ of mothers had the knowledge that complementary feeding should be started by $6-7$ months, $25.8 \%$ by $8-10$ months, $21.2 \%$ by $11-12$ months, $1.4 \%$ by $>12$ months and $0.6 \%$ had no idea about complementary feeding.

Source of information, attitude and reasons for complementary feeding were assessed in 500 mothers. 281/500 mothers did complementary feeding by self or previous experience, 183/500 mothers had information from family or friends, $152 / 500$ mothers received information from health personnel. Most of them had information from more than one source.

Most of the mothers (345/500) started complementary feeding because of insufficient milk, 186/500 mothers started complementary feeding as they felt the child required more than milk. Most common reason for delayed complementary feeding among 80/500 mothers, was the child not accepting complementary feeding foods or vomiting.

The mean age of complementary feeding in this study, was $8.24 \pm 2.79$ months and range 3 to 18 months. $23 \%$ of mothers started complementary feeding at 6 months of age, $8.2 \%$ by $4-5$ months, $15.8 \%$ by 7 months, $22.6 \%$ by $8-9$ months, $20.6 \%$ by $10-12$ months, $3.4 \%$ by $13-24$ months and $0.2 \%$ started complementary feeding $<4$ months of age. $6.2 \%$ have not started complementary feeding.

The mean age of complementary feeding according to socio economic status in class I was $6.37 \pm 0.52$ months, the mean age of complementary feeding in class II was $6.71 \pm 1.74$ months, the mean age of complementary feeding in class III is $6.89 \pm 1.54$ months, the mean age of complementary feeding in class IV was $8.91 \pm 2.61$ months and the mean age of complementary feeding in class V was $12.04 \pm 3.45$ months. The mean age of complementary feeding in class I, II, III was compared with class IV and V, with p value $<0.001$, which was highly significant.

The age of complementary feeding and its effect on nutrition of the child was assessed. $34.1 \%$ children were under weight, $34.5 \%$ children were stunted and $23.8 \%$ were wasted according to WHO classification. In children where complementary feeding was started at 6 months of age, $15.8 \%$ were under weight, $14.0 \%$ stunted and $17.5 \%$ wasted.

When complementary feeding was started after 6 months of age, $48.85 \%, 46.05 \%$ and $33.10 \%$ were under weight, stunted and wasted respectively. Complementary feeding started after 12 months in children showed that $71.9 \%$, $75.1 \%$ and $29.3 \%$ were under weight, stunted and wasted respectively. 
Table-2: Factors influencing age of complementary feeding $(M=$ Mean age of complementary feeding in months and $p$ value.

\begin{tabular}{|c|c|c|}
\hline Factors & Mean age of complementary feeding & \multirow{2}{*}{ p value } \\
\hline Male &, $\mathrm{M}=8.53 \pm 3.04$ & \\
\hline Female & $\mathrm{M}=7.90 \pm 2.52$ & $\mathrm{p}>0.05$ \\
\hline Primi gravid & $\mathrm{M}=8.08 \pm 2.83$ & \\
\hline Multi gravid & $\mathrm{M}=8.35 \pm 2.76$ & $\mathrm{p}<0.001$ \\
\hline Literate & $\mathrm{M}=7.4 \pm 1.95$ & \\
\hline Illiterate & $\mathrm{M}=9.35 \pm 3.31$ & $\mathrm{p}>0.05$ \\
\hline Working & $\mathrm{M}=8.75 \pm 3.16$ & $\mathrm{p}<0.001$ \\
\hline House wife & $\mathrm{M}=8.11 \pm 2.68$ & \\
\hline Urban & $\mathrm{M}=7.64 \pm 2.56$ & \\
\hline Rural & $\mathrm{M}=8.78 \pm 2.88$ & \\
\hline
\end{tabular}

Table-3: Factors Influencing Age of Complementary feeding

\begin{tabular}{|c|c|c|c|c|c|c|c|c|}
\hline & \multicolumn{2}{|c|}{ Sex } & \multicolumn{2}{|c|}{ Parity } & \multicolumn{2}{|c|}{ Education } & \multicolumn{2}{|c|}{ Occupation } \\
\hline $\begin{array}{l}\text { Age of } \\
\text { complementary } \\
\text { feeding (months) }\end{array}$ & Male & Female & Primi & Multi & Literate & Illiterate & Working & Housewife \\
\hline$<4$ & 1 & 0 & 0 & 1 & 1 & 0 & 0 & 1 \\
\hline $4-5$ & 23 & 18 & 19 & 22 & 25 & 16 & 8 & 33 \\
\hline $6-7$ & 92 & 102 & 89 & 105 & 143 & 51 & 35 & 159 \\
\hline $8-9$ & 63 & 50 & 49 & 64 & 63 & 50 & 20 & 93 \\
\hline $10-12$ & 60 & 43 & 32 & 71 & 34 & 69 & 29 & 74 \\
\hline $13-24$ & 15 & 2 & 9 & 8 & 1 & 16 & 4 & 13 \\
\hline Not Started & 15 & 16 & 10 & 21 & 9 & 22 & 6 & 25 \\
\hline Total & 269 & 231 & 208 & 292 & 276 & 224 & 102 & 398 \\
\hline Mean & 8.53 & 7.90 & 8.08 & 8.35 & 7.4 & 9.35 & 8.75 & 8.11 \\
\hline S. D. & 3.04 & 2.52 & 2.83 & 2.76 & 1.95 & 3.31 & 3.16 & 2.68 \\
\hline Z Value & \multicolumn{2}{|c|}{2.53} & \multicolumn{2}{|c|}{1.06} & \multicolumn{2}{|c|}{7.79} & \multicolumn{2}{|c|}{1.88} \\
\hline P Value & \multicolumn{2}{|c|}{$<0.05$} & \multicolumn{2}{|c|}{$>0.05$} & \multicolumn{2}{|c|}{$<0.001$} & \multicolumn{2}{|c|}{$>0.05$} \\
\hline
\end{tabular}

Factors influencing age of complementary feeding was assessed. Our study showed male child is weaned late than the female child $(\mathrm{p}<0.05)$. In Savage et al study they found no difference between sex of child and age of complementary feeding which is in contradiction to our study.

This may be due to prolonged breast feeding of male child without starting feeding. More studies are required relating sex of child and age of complementary feeding.

Illiterate mothers tend to wean late than the literate mothers, which is statistically highly significant $(\mathrm{p}<0.001)$.

Rural mothers wean late than the urban mothers, which is statistically highly significant $(\mathrm{p}<0.001)$. 
There was no significant relation between age of complementary feeding and parity of the mother, occupation and religion of the mother.

Table-4: Comparison between Age of Complementary feeding started and Malnutrition

\begin{tabular}{|c|c|c|c|c|}
\hline $\begin{array}{c}\text { Age of } \\
\text { complementary } \\
\text { feeding (months) }\end{array}$ & $\begin{array}{c}\text { No. of } \\
\text { children's }\end{array}$ & Weight for Age & Length for Age & $\begin{array}{c}\text { Weight for } \\
\text { Length }\end{array}$ \\
\hline$<6$ & & Under weight \% & Stunted \% & Wasted \% \\
\hline 6 & 42 & 11.7 & 20.3 & 18.2 \\
\hline $7-8$ & 115 & 15.8 & 14.0 & 17.5 \\
\hline $9-11$ & 139 & 22.9 & 26.0 & 18.0 \\
\hline $12-24$ & 85 & 45.8 & 44.4 & 36.6 \\
\hline Not started & 88 & 71.9 & 75.1 & 29.3 \\
\hline Total & 500 & 54.8 & 38.7 & 48.4 \\
\hline
\end{tabular}

In our study, $34.1 \%$ children were under weight, $34.5 \%$ children were stunted and $23.8 \%$ were wasted, around $70 \%$ of the children were malnourished when complementary feeding was started beyond 12 months, while only around $15 \%$ of children were malnourished when complementary feeding was started by 6 months. Hence, there is significant association between delayed complementary feeding and malnutrition of the child.

\section{Discussion}

Knowledge, attitude and practices of complementary feeding were assessed in 500 mothers with children aged between 6 to 24 months of age. The mean age of knowledge regarding complementary feeding in this study was 7.99 months which is more than the recommended 6 months. Only $34.2 \%$ of mothers had the knowledge that complementary feeding should be started by 6 months, which was less than the study conducted in Delhi (46\%) by Anju Aggarwal et al[6]. Hence, the knowledge regarding timely complementary feeding, feeding practices, recommendations and guidelines was lacking and inadequate. Mothers were not aware about the medical problems associated with late complementary feeding. Similar results were obtained by Frazeir et al study[7] and Anju Aggarwal et al study.[6].

In the present study, information regarding complementary feeding was received from health persons in only 152 out of 500 mothers, which is very less. Majority of the mothers did complementary feeding by self or previous experience and others had information from family or friends. Literature and media played a very minimal role in educating mothers regarding proper complementary feeding practices. There are very few Indian studies, about source of information regarding complementary feeding.

In the present study, most of the mothers started complementary feeding as they felt that their milk was not enough or insufficient and there was increased requirement by the child. There are many other studies, which have obtained similar reasons for complementary feeding.[6,9].

The main reasons for delayed complementary feeding were, not knowing the time when to start complementary feeding, misconceptions, customs and false beliefs prevalent in the community. Anju Aggarwal et al study in Delhi also states that, delayed complementary feeding practices are due to poor knowledge, customs and beliefs [6].

The other reason for delayed complementary feeding was child not accepting or vomiting. Similar reasons for delayed complementary feeding were obtained in Anju Aggarwal et al study [6] and other studies also.[10,11]. It was actually not vomiting but it was the child spitting out the food or not liking the taste of food. Hence, the mothers should be educated that the child has to develop the taste of foods and if they attempt and keep the food on child's tongue, the child slowly 
will like it and start swallowing. It is important for the parents to know that feeding a child is a gradual process, which needs continuous trial and support.

Table -5: Mean age of complementary feeding in various studies

\begin{tabular}{|l|c|}
\hline Studies & $\begin{array}{c}\text { Mean age of complementary feeding } \\
\text { (months) }\end{array}$ \\
\hline WHO recommendation & 6 \\
\hline Singh et al (Rajasthan) & 8.70 \\
\hline Anju Agarwal et al (Delhi) & 13.37 \\
\hline Isherwood RJ et al (Bangladesh) & 13.50 \\
\hline M.E. Khan (Tamilnadu) & 9.0 \\
\hline M.E. Khan (West Bengal) & 7.7 \\
\hline Present study & 8.24 \\
\hline
\end{tabular}

The mean age of complementary feeding or complementary feeding in the present study was 8.24 months, which was far beyond the recommended age of 6 months by WHO and there is a definite delay in starting complementary feeding. In Singh et al study, the mean age of complementary feeding was 8.7 months in semi-arid rural areas of Rajasthan which is comparable to the present study.[12] The variation in mean complementary feeding age may be due to difference in knowledge, customs, beliefs, practices and educational status of the mothers.

Comparison of Mean Age of Complementary feeding in Various Studies: In this study, $23 \%$ of the mothers started complementary feeding at 6 months of age which is comparable to the studies done by Chaturvaedi et al in Agra(20\%)[10] and Anju Aggarwal et al in Delhi (17.5\%)[6]. The percentage of mothers practicing timely complementary feeding at 6 months in infants is very less in this study.

Comparison of Commercial Foods Used:Mothers thought that commercial food are good for the babies and it gives lot nutrition in our study $12.03 \%$ of the mothers who had started commercial foods, got information from the health workers. They thought that, these commercial foods are better and stronger and easy to prepare than homemade foods. The practice of starting commercial foods is more in urban mothers and there is a rise in the usage of commercial foods. Banapurmath et al study commercial food used by mothers were 5.3\%[8], Pant I and chotia et al study, 50\% of mothers used commercial food[9], and Khoklar et al 37\% of mothers used commercial food.[15]

Comparison of Nutrition Status of Children in Various Places: In our study, $34.1 \%$ children were under weight, 34.5 $\%$ children were stunted and $23.8 \%$ were wasted of the total children, this is comparable to NFHS-3 Data (India) - (41.4 $\%, 38.0 \%$ and $17.9 \%$ ) and (45.9\%, $38.4 \%$ and $19.4 \%)$ as per NFHS-3 data(Karnataka).[14] In Medhi.G.K et al study, $64.6 \%, 41.7 \%$ and $39.6 \%$ were under weight, stunted and wasted respectively, which is more than the present study due to improper feeding practices.[16]

Factors Influencing Age of Complementary feeding: Illiterate mothers wean their kids late than the literate mothers, which is statistically highly significant $(\mathrm{p}<0.001)$. There are many other studies, which support our findings that maternal illiteracy is associated with delayed and inappropriate feeding practices.[10,12]

Rural mothers wean late than the urban mothers, which is statistically highly significant $(\mathrm{p}<0.001)$. Similar results were found in Singh et al study and Chaturvaedi et al study, which state that rural mothers practice improper and delayed complementary feeding.[12,10]

There was no significant relation between age of complementary feeding and parity of the mother, occupation and religion of the mother. There are no comparison studies for this and more studies are required in this aspect Our study showed male child is weaned late than the female child $(\mathrm{p}<0.05)$. In Savage et al study they found no difference 
between sex of child and age of complementary feeding which is in contradiction to our study. This may be due to prolonged breast feeding of male child without starting feeding. More studies are required relating sex of child and age of complementary feeding.

Comparison between Age of Complementary feeding started and Malnutrition: In our study, $34.1 \%$ children were under weight, $34.5 \%$ children were stunted and $23.8 \%$ were wasted, this is comparable to Karnataka - $(41.4 \%, 38.0 \%$ and $17.9 \%)$ and Indian statistics - (45.9\%, $38.4 \%$ and $19.4 \%)$ as per NFHS-3 data.[14].

In the present study, around $70 \%$ of the children were malnourished when complementary feeding was started beyond 12 months, while only around $15 \%$ of children were malnourished when complementary feeding was started by 6 months. Hence, there is significant association between delayed complementary feeding and malnutrition of the child. Similar relation between delayed complementary feeding and malnutrition was obtained by Khokhar et al study[15], Sabu et al study[17].

\section{Conclusion}

Mother's knowledge regarding complementary feeding time is inadequate and practices are inappropriate. Majority of them are not aware of the current recommendations and proper way of doing it. Correct information and guidelines about complementary feeding is not reaching the target population. Because of False beliefs, customs and attitude of the mother tend to wean the child late where the babies are landing up in severe problem.

Mean age of complementary feeding is delayed due to improper information and child not accepting complementary feeding foods. Other factors influencing delayed complementary feeding are male child, illiteracy, low socio-economic status and rural mothers. Parity of the mother, occupation and religion of the mother has no influence on age of complementary feeding.

There is significant association between delayed complementary feeding and malnutrition of the child. Poor breastfeeding and inappropriate complementary feeding practices are the principal proximate causes of malnutrition during the first two years of life.

Hence it is essential, that accurate information and education should be given to mothers and caregivers about appropriate timing of initiating complementary feeding, complementary feeding foods, preparation and practices to prevent malnutrition and improve the health status of the children.

\section{Bibliography}

1. Elizebeth KE. Nutrition and child development, Paras medical publisher, $3^{\text {rd }}$ revised edn, 2007; 23-28.
2. Ruth. A Lawrence and Robert. M Lawrence. Breast feeding a guide for the medical profession; Elsevier publications, $6^{\text {th }}$ edn, $2005 ; 357-375$.

3. Vossenaar M, Doak CM, Solomons NW. Challenges in the elaboration of a field interview instrument to capture information for the evaluation of adherence to the WHO/PAHO Guiding Principles for Complementary Feeding of the Breastfed Child. Food Nutr Bull. 2014 Sep;35(3):338-50.

4. WHO. Global Strategy for Infant and Young Child Feeding. Geneva: World Health Organization. WHA55/2002/REC/1 Annex 2, 2002.

5. WHO Anthro for personal computers, version 2, 2007: Software for assessing growth and development of the world's children. Geneva: WHO, 2007. http://www.who.int/childgrowth/software.

6. Aggarwal A, Verma S, Faridi M; Dayachand. Complementary feeding--reasons for inappropriateness in timing, quantity and consistency. Indian $J$ Pediatr. 2008 Jan;75(1):49-53.

7. Frazier JP, Countie D, Elerian L. Parental barriers to weaning infants from the bottle. Arch Pediatr Adolesc Med. 1998 Sep;152(9):889-92.

8. Banapurmath CR, Nagaraj MC, Banapurmath $\mathrm{S}$, Kesaree N. Breastfeeding practices in villages of central Karnataka. Indian Pediatr. 1996 Jun;33(6):4779.

9. Pant I, Chothia K. Maternal knowledge regarding breast feeding and weaning practices. Indian $\mathrm{J}$ Pediatr. 1990 May-Jun;57(3):395-400. 
10. Chaturvedi M, Nandan D, Gupta SC. Rapid assessment of infant-feeding practices in Agra district. Indian J Community Med 2007; 32:227.

11. Ganjoo C, Rowlands R. Breast feeding and weaning practices of urban housewives in Srinagar. Indian J Nutr Diet. 1988 Nov;25(11):354-8.

12. Singh MB, Haldiya KR, Lakshminarayana J. Infant feeding and weaning practices in some semi-arid rural areas of Rajasthan. J Indian Med Assoc. 1997 Nov;95(11):576-8, 590.

13. Khan ME. Breast-feeding and weaning practices in India. Asia Pac Popul J. 1990 Mar;5(1):71-88.

14. NFHS-3.National Family Health Surveys, National fact sheet - India and Karnataka. 2007. www.nfhsindia.org.
15. Khokhar A, Singh S, Talwar R, Rasania SK, Badhan SR, Mehra M. A study of malnutrition among children aged 6 months to 2 years from a resettlement colony of Delhi. Indian J Med Sci. 2003 Jul;57(7):286-9.

16. Medhi GK, Mahanta J. Breastfeeding, weaning practices and nutritional status of infants of tea garden workers of Assam. Indian Pediatr. 2004 Dec;41(12):1277-9.

17. Sabu s padmadas, Inge hutter and Frans willekens. Complementary feeding initiation patterns and subsequent linear growth progression among children aged $2-4$ years in India. International journal of epidemiology 2002; 31:855-863.

\section{How to cite this article?}

Venugopal S., Chandrashekar. Knowledge of complementary feed and its effect on the child nutrition. Pediatr Rev: Int J Pediatr Res 2016;3(1):24-31.doi:10.17511/ijpr.2016.i01.06. 